\title{
CONSIDERAÇÕES PSICANALÍTICAS SOBRE O PROJETO DE LEI ESCOLA SEM PARTIDO
}

\section{PSYCHOANALYTICAL CONSIDERATIONS ON THE PROPOSAL NO PARTY SCHOOL}

\author{
Marina Sodré. ${ }^{79}$ \\ Carolina Carvalho Dutra. ${ }^{80}$
}

\begin{abstract}
Resumo
A partir de uma leitura lacaniana, este trabalho tem como objetivo discutir a expansão do discurso da ciência na educação brasileira atual. Para tal, tomamos como ponto de partida a proposta do projeto de lei Escola Sem Partido. Este projeto de lei pretende instituir nos sistemas de ensino a proibição legal de qualquer conteúdo curricular que possa ser conflitante com as convicções morais dos pais, tratando-se da defesa da neutralidade em contraposição à suposta doutrinação político-ideológica do professor. Se em Freud educação e civilização se confundem, indagamo-nos se é possível haver um discurso que não seja político-ideológico.
\end{abstract}

Palavras-chave: Escola sem partido. Discurso da ciência. Neutralidade. Política. Ideologia.

\begin{abstract}
From a Lacanian reading, this work aims to discuss the expansion of the discourse of science in the current Brazilian education. To do this, we take as a starting point the proposal of the "No Party School" bill. This bill aims to institute in education systems the legal prohibition of any curricular content that could be conflicting with the moral convictions of the parents, being the defense of neutrality as opposed to the alleged political-ideological indoctrination of the teacher. If in Freud education and civilization are confused, we ask ourselves if it is possible to have a discourse that is not politicalideological.
\end{abstract}

Keywords: No party school. Science discourse. Neutrality. Politics. Ideology.

\footnotetext{
79 Doutora em Psicanálise pelo Programa de Pós-graduação em Psicanálise da Universidade do Estado do Rio de Janeiro. Prefeitura da Cidade do Rio de Janeiro, Secretaria Municipal de Educação. E-mail: marinasodre@yahoo.com.br; Telefone: (21) 996346078; ORCID: https://orcid.org/0000-0002-6024-3683.

80 Mestranda em Psicologia pelo Programa de Pós-graduação em Estudos da Subjetividade da Universidade Federal Fluminense. E-mail: linadutra@yahoo.com.br; Telefone: (21) 988814994; ORCID: https://orcid.org/0000-0001-5775-782X.
} 


\section{RevistAleph}

\section{Introdução}

Este trabalho é fruto da inquietação das autoras diante do Projeto de Lei Escola sem Partido. Indagamo-nos sobre as possíveis contribuições da psicanálise para o debate estabelecido entre profissionais da educação e políticos; indagação que nos levou a entender o Projeto de Lei Escola sem Partido como expressão da expansão da chamada tecnociência na educação brasileira atual. A disposição teórico-metodológica está estruturada em revisão bibliográfica, sendo um trabalho de caráter autoral, desvinculado de projetos ou programas de pesquisa.

\section{O Projeto de Lei Escola sem Partido}

Em vários municípios e estados, também no âmbito federal brasileiro, o Projeto de Lei $n^{\circ}$ 867, de 2015, pretende instituir nos sistemas de ensino o "Programa Escola sem Partido", que inclui entre as diretrizes e bases da educação nacional os princípios de neutralidade política, ideológica e religiosa do Estado. Embora apresente o propósito de promover o pluralismo de ideias no ambiente escolar, a liberdade de aprender, de ensinar, de consciência e de crença, propõe primazia aos valores de ordem familiar sobre a educação escolar nos aspectos relacionados à educação moral, sexual e religiosa. Diante da pluralidade de valores culturais dos estudantes e suas famílias, como atender às referências morais e religiosas de cada núcleo familiar? Essa questão por si só, nos parece, já inviabilizaria tal Projeto de Lei.

A proposta prevê que as escolas deverão afixar cartazes nas salas de aula com o conteúdo da lei, bem como nas salas dos professores e em locais onde possam ser lidos por estudantes e docentes, com o conteúdo previsto que estabelece que estes últimos não podem usar sua posição para cooptar alunos para qualquer corrente política, ideológica ou partidária. Os limites descritos no projeto de lei restringem as políticas, os planos educacionais e os projetos pedagógicos das escolas especialmente 


\section{RevistAleph}

no que se refere à discussão de gênero, seara que é tratada pelos relatores como uma forma de dogmatismo.

As alterações da Lei de Diretrizes e Bases da Educação pretendidas pelo Projeto deverão ser informadas a professores, estudantes, pais e responsáveis. Planeja-se que haverá canais de comunicação destinados ao recebimento de reclamações relacionadas ao descumprimento desta Lei, sendo assegurado o anonimato. Tais reclamações seriam então encaminhadas ao órgão do Ministério Público incumbido da defesa dos interesses da criança e do adolescente, sob pena de responsabilidade. Vemos, assim, que o Projeto Escola sem Partido impõe um ambiente de vigilância sobre o professor e suas práticas pedagógicas.

As novas normas abrangeriam tanto escolas públicas quanto particulares. $\mathrm{Na}$ educação básica, os colégios privados poderiam veicular e promover os conteúdos de cunho religioso, moral e ideológico autorizados contratualmente pelos pais ou responsáveis pelos estudantes. Dentre essas diretrizes, parece-nos que a dita neutralidade é o ponto chave do documento, visto que é a sua própria justificativa. A proposição se baseia na ideia de que há, na relação de aprendizado, uma "vulnerabilidade" do educando, sendo este "a parte mais fraca" do par professor-aluno:

É fato notório que professores e autores de materiais didáticos vêm se utilizando de suas aulas e de suas obras para tentar obter a adesão dos estudantes a determinadas correntes políticas e ideológicas para fazer com que eles adotem padrões de julgamento e de conduta moral especialmente moral sexual - incompatíveis com os que lhes são ensinados por seus pais ou responsáveis (PLS 193/2016).

Em razão deste "fato notório", propõe-se "adotar medidas eficazes para prevenir a prática da doutrinação política e ideológica nas escolas" e garantir aos pais o direito à educação religiosa e moral que esteja de acordo com as suas conviç̧ões. Assim, embora o texto do Projeto de Lei traga a liberdade como uma diretriz, o movimento de mesmo nome, formado por pais e educadores defensores da proposta, se posiciona contra o que chama de "abuso da liberdade de ensinar". ${ }^{81}$

${ }^{81}$ Disponível em:<http://www.programaescolasempartido.org/>. Acesso em 18/09/2016. 


\section{RevistAleph}

\section{A Tecnociência}

A partir de leituras lacanianas, compreendemos a defesa da "neutralidade" em substituição a "ideologia" como uma face da influência do discurso contemporâneo da ciência na educação. Voltolini, em "O discurso do capitalista, a psicanálise e a educação" (2007), explora a ideia de que em nossos dias a ciência ganha contornos específicos, distanciando-se da ciência em seu sentido mais clássico. Esse movimento atual da ciência, segundo o autor, tem como uma de suas características fundamentais a prevalência da dimensão técnica sobre a dimensão investigativa, sendo apelidada por isso de tecnociência. Para o autor, uma característica fundamental da tecnociência é a crença na possibilidade de haver enunciado sem enunciação. Enunciado e enunciação estão, no discurso da linguística, conjugados, entretanto para Lacan (19571958/inédito), ambos estão dissociados, estando endereçado ao sujeito do inconsciente a primazia da enunciação.

A ciência contemporânea, na tentativa de se desvencilhar da enunciação, valoriza o uso de uma linguagem utilitária e a produção de objetos descartáveis e substituíveis, caindo em desuso a produção de ideias. O conceito de tecnociência é destacado por Voltolini, pois a ciência seria posta como uma prestadora de serviço, que criaria e organizaria seus métodos de modo a "experimentar, calcular, verificar, prever, avaliar e inovar", significantes-mestres apontados por Voltolini (2007), aos quais podemos acrescentar "prevenir". Tais significantes nomeiam a pretensão de dominação e controle das relações sociais, inclusive da relação professor e aluno, em que se deve "prevenir a doutrinação ideológica".

Como consequência para o campo da educação, temos algo apontado por Rahme e Mrech (2010), a saber, que os professores participam cada vez menos das decisões que afetam a sua prática profissional e são cada vez mais gerenciados e controlados. No movimento atual da ciência, o professor é entendido como um tecnocrata, e não mais como um artesão. Um professor de filosofia, imaginemos, deve 


\section{RevistAleph}

se precaver para não filosofar em sala de aula, apenas repetindo certas concepções de pensadores. É vetado ao professor de dança o lugar de artista, de autoria e criação, restando a ele as técnicas corporais.

Voltemos às consequências da lógica da tecnociência sobre a função do professor. O discurso da tecnociência nega a sua conexão com o Outro; coloca-se, como se houvesse esta possibilidade, enquanto um discurso sem Outro. Sob a perspectiva lacaniana (1998 [1950]), não há discurso sem Outro, e um discurso que não reconhece esta ligação com o Outro implicaria em uma desresponsabilização em relação às suas consequências, já que a noção lacaniana de responsabilidade diz respeito ao modo como o sujeito responde à emergência do real incluindo o Outro. Apenas uma resposta que inclua o Outro é uma resposta possível e responsável.

Responsabilização, nesse sentido, não se baseia no cumprimento de normas jurídicas, como espera o Projeto de Lei Escola sem Partido, que pode ser inserido no processo atual de judicialização da educação. Já no sentido lacaniano, resposta responsável é subjetiva, singular e não-prescritiva. Assim, entendemos que o Projeto de Lei Escola sem Partido é um discurso cujo agente não responde pelas consequências de sua produção. Um discurso que se crê não ideológico é um discurso que se crê sem Outro, desimplicado, portanto, de sua responsabilidade. Nesse sentido, a bandeira da "neutralidade" escamoteia a face totalitária que Voltolini (2007) reconhece na tecnociência.

\section{Educação, Tecnociência e Escola sem Partido}

A homogeneização, a ideologia da medida e a demanda de avaliação são instrumentos de expansão da tecnociência, a partir dos quais esta exerce determinante influência não só nas diversas áreas do conhecimento, como também nas variadas políticas públicas, inclusive no campo da educação. A lógica aí presente nos remete ao que Lacan (2001 [1966]) descreveu em 1966 em relação à nova função do médico inaugurada pelo avanço da ciência. 


\section{RevistAleph}

Lacan discorreu sobre a entrada da medicina numa fase científica, cujos efeitos seriam as modificações na função social do médico e na demanda de cura dos pacientes. Efeito mais importante ainda, Lacan indicou a existência de uma aceleração quanto ao lugar da ciência na vida comum, e o consequente aparecimento de um "novo" modo de ser, adaptado às condições de um mundo científico.

A medicina científica, dotada de novos poderes de investigação e pesquisa, passou a se apresentar como um discurso cujo poder é generalizado. Passou ainda a se organizar como uma empresa, sendo inserida na lógica da produtividade, da medida, do controle, dos gráficos e afins. Nesse contexto, novas demandas são dirigidas ao médico.

O mundo científico deposita em suas mãos o número infinito daquilo que é capaz de produzir em termos de agentes terapêuticos novos, químicos ou biológicos. Ele os coloca à disposição do público e pede ao médico, assim como se pede a um agente distribuidor, que os coloque à prova (LACAN, 2001 [1966]: p. 10).

De forma bastante crítica, Lacan demonstra como a medicina, colocada nas mãos da ciência, deforma o direito à saúde, tornando-o uma espécie de toxicomania, com a proliferação de produtos ofertados ao público. A demanda de cura, portanto, é uma demanda de consumo dos objetos da ciência. Parece-nos que a expansão desta na vida comum das pessoas também altera as demandas sociais dirigidas à educação e ao professor, que passa a ser parte de uma espécie de organização empresarial, regida por metas, produtividade, controles quantitativos e assim por diante.

As autoras Rahme e Mrech (2010) reconhecem a influência da perspectiva cognitivista sobre a educação como uma das vertentes da expansão da tecnociência, já que tal perspectiva prioriza os métodos sobre os outros aspectos do processo de ensinoaprendizagem, gerando as práticas de controle de métodos. É o que se passa, por exemplo, nos programas de "aceleração da aprendizagem" comprados pela Secretaria Municipal de Educação do Rio de Janeiro, na gestão da Cláudia Costin, do Instituto Ayrton Senna ${ }^{82}$. A Secretaria comprou do Instituto uma "solução" para o "fracasso

\footnotetext{
82 O Instituto Ayrton Senna é uma organização sem fins lucrativos, que se propõe a atuar na produção, sistematização e disseminação de conhecimento científico para a formulação, implementação e avaliação de políticas públicas que promovam uma educação integral. Disponível em: <https://institutoayrtonsenna.org.br/pt-br.html>. Acesso em: 13/04/2019.
} 


\section{RevistAleph}

escolar" de parte dos alunos da rede. A "solução" é um pacote pronto de metodologias, conteúdos pedagógicos e materiais didáticos que são "aplicados" por professores da rede em turmas de alunos com defasagem série/idade. A "solução" não implica a escola, o professor, o aluno ou a família. Professor e escola ficam no lugar de mero executores da suposta solução, perdendo autonomia, criatividade e particularidade.

Em entrevista realizada por Miller, o pedagogo francês Philippe Meirieu (2008) também chama a atenção para as consequências da hegemonia do cognitivismo, do comportamentalismo e do biologicismo para os dias de hoje, remetendo-nos inclusive ao cenário do livro de Aldous Huxley (2009 [1946]), Admirável Mundo Novo. Segundo o pedagogo, tais ciências, preocupadas em descrever os seres humanos através de maquinarias lógico-matemáticas, ou por fatores bioquímicos, reduzem-no a um objeto padronizável e calculável, sendo, portanto, suscetível a diversas formas de controle.

Jacques-Alain Miller (2007-2008) propõe uma reflexão acerca do discurso da ciência contemporânea, afirmando que os modos como a sociedade vêm atuando são reflexo direto das incidências da matemática, através de seu discurso, e da aceleração da ciência. Aos poucos, este discurso vai se incorporando aos nossos modos de vida, gerando uma demanda de quantificação. Supõe-se que a ciência seja imaculável, que uma vez comprovada não há mais nada a fazer a não ser aceitá-la.

Essa intenção da homogeneidade do discurso tende à comparação, à avaliação. O número que quantifica passa a ser a garantia do ser. É a ciência atuando sobre a ontologia do ser. Se algo não for cifrável, é como se não existisse. O sujeito, para a psicanálise, é o inverso deste, pois pressupõe um sujeito incomparável, que está agarrado a um significante, e deste modo é um sujeito não homogeneizável, não categorizável. A ciência se afirma cada vez mais, e assim pode ser verificado o movimento da cultura de se apoderar do discurso biológico. Miller nos chama atenção para o fato de que o começo disso está no desejo dos humanos, desejo de que tudo seja da ordem do quantificável.

A tecnociência, sendo um discurso que se compõe trançando ciência e tecnologia, busca cifrar a norma, mensurar a eficiência e, deste modo, lança uma mudança drástica na relação do sujeito com seu próprio corpo e sua experiência 


\section{RevistAleph}

subjetiva. Certamente a história da evolução de nossa civilização está atravessada pela tecnologia, mas se, assim como a ciência, pretende acabar com o mal que acomete o sujeito, o que se produz é desapontamento e decepção. O Projeto de Lei Escola sem Partido pressupõe sujeitos não partidos, sem divisão.

Freud, em "O mal-estar na civilização" (1996 [1930]), já indicava que o avanço da tecnologia e da medicina não trazia mais satisfação ao ser humano. De acordo com sua "voz crítica pessimista", os avanços científicos proporcionam ao sujeito uma satisfação no modelo do "prazer barato": "o prazer obtido ao se colocar a perna nua para fora das roupas de cama numa fria noite de inverno e recolhê-la novamente" (FREUD, 1996 [1930], p. 95).

Uma política educacional fomentada por tais ciências e por seus ideais quantitativos e funcionais transforma a educação em uma prática totalizante, e até mesmo totalitária, em que educadores são "tecnocratas" e "todos os alunos podem aprender". Nessa perspectiva, o ato pedagógico é definido como uma "racionalidade instrumental", sustentada pela fantasia de uma "tecnologia pedagógica superpoderosa" e pela negação daquilo que escapa à educabilidade (MEIRIEU, 2008).

Tizio (2003) observa que, com a expansão dos discursos da ciência e do capitalista na educação, o saber não se ancora mais na autoridade epistêmica, mas em uma nova modalidade de autoridade, a autoridade da burocracia, da avaliação e da técnica, o que desencadeia uma abstenção generalizada do exercício da autoridade. A articulação entre saber e enunciação, tão rica para a psicanálise, é substituída pela "autoridade" da medida.

A tecnologia, por fim, negaria a corrente inconsciente presente nas relações escolares, aspecto tão valorizado por Freud em Algumas reflexões sobre a psicologia do escolar (1914a). Para o criador da psicanálise, os caminhos do conhecimento passam pelo interesse particular do aluno pela personalidade do mestre-professor, ou seja, o ensino se dá via a chamada transferência. Nessa perspectiva, o chamado "processo de ensino-aprendizagem" não é um fenômeno da ordem da consciência e da intenção, como fazem crer as tecnologias de ensino, mas se dá por uma transmissão, justamente por aquilo que se apresenta à nossa revelia. 


\section{RevistAleph}

Metáfora interessante de Voltolini (2011), o ensino, para a psicanálise, é como a transmissão de um vírus que espalhamos sem intenção ou consciência, sem querermos ou mesmo sabermos. Nesse sentido, não há aprendizagem sem enunciação. A lógica da tecnociência, que dita soluções para os problemas da educação brasileira, acaba por inviabilizar a transmissão. Nos parece que o projeto Escola sem Partido pressupõe algo irrealizável, que seria proibir, em última instância, o inconsciente.

\section{Considerações Finais}

A pretensão de gerenciamento e de controle das relações sociais subtendida na tecnociência aparece de forma bastante nítida no caso do Projeto de Lei Escola sem Partido, que visa excluir o mal-estar, o mal-entendido, o desencontro entre professor e aluno. Em contraposição, a psicanálise nos ensina que o mal-entendido faz parte da cena escolar e da situação de aprendizagem por questões estruturais da linguagem,

[...] no se trata solamente de cadenas significantes, no se trata solamente de palabras, ya que desde Freud la clínica psicoanalítica ha demostrado que lo proprio de los seres hablantes es que se malentienden. $Y$ se mal-entienden porque en todo intercambio con los otros hay en juego una satisfacción. No se intercambiam solo palabras, también hay el deseo, la libido, trenzada en el lenguaje. El lenguaje está enganchado a lo vivo ${ }^{83}$ (AROMí, 2003, p. 129).

É claro que não acreditamos no sucesso da tecnociência em fazer desaparecer toda a sorte de mal-entendido das relações sociais. Porém, tal tentativa não é sem efeitos para a prática educativa e para o cotidiano escolar. Nas mãos da tecnociência, a educação e o ensino são tratados como mais um produto disponível no mercado para o consumo. Um produto altamente rentável, ousamos afirmar. Permitindo-nos criar uma

\footnotetext{
83 Tradução nossa: "não se trata somente de cadeias significantes, não se trata somente de palavras, já que desde Freud a clínica psicanalítica tem demonstrado que o próprio dos seres falantes é que se mal-entendem. $E$ se mal-entendem porque em todo intercâmbio com os outros tem em jogo uma satisfação. Não se intercambiam apenas palavras, também há o desejo, a libido, trançada na linguagem. A linguagem está enganchada no vivo".
} 


\section{RevistAleph}

imagem, o Projeto de Lei Escola sem Partido parece criar uma espécie de Procon desse grande produto consumidor que é atualmente o ensino.

É de fundamental importância a garantia do acesso da população à educação, sublinhando que na comunidade escolar deve haver uma abertura para o que é peculiar ao sujeito. Ao inibir discussões sobre gênero e orientação sexual, por exemplo, a proposta impede avanços para combater a discriminação e, consequentemente, para reduzir os crimes de ódio, que possuem em estatísticas assustadoras a demonstração do crescimento desses crimes no país.

Partindo da compreensão de que a psicanálise é constantemente atravessada pelo seu tempo, pela cultura e pela produção de subjetividade de cada época, acompanhamos Voltolini (2011) em sua proposta de defender a educação do discurso da tecnociência. A partir da psicanálise, demonstramos que não há fala que não seja político-ideológica e que a não-ideologia é, antes de tudo, uma ideologia. Ao assumir esta prerrogativa, não preconizamos, ao contrário do que alguns querem nos convencer, a submissão do aluno ao professor, mas justamente corroboramos com a noção de responsabilização de todos os atores envolvidos no processo escolar.

Afinal, se política, do Grego: roגıtıós/politikos, significa "de, para, ou relacionado a grupos que integram a Pólis", podemos afirmar que não é possível um discurso que não seja político-ideológico. Diante desse fato de estrutura, o que nos cabe é estarmos advertidos de que por trás de todo enunciado há a enunciação, o que desloca o foco da "neutralidade" para a questão da ética na educação.

\section{Referências}

AROMí, Anna. De dónde parte el psicoanálisis?. In: TIZIO, Hebe (orgs). Reinventar el vínculo educativo: aportaciones de la Pedagogía Social y del Psicoanálisis. Barcelona: Gedisa, 2003.

FREUD, Sigmund. Algumas reflexões sobre a psicologia do escolar (1914a). In: Obras

Psicológicas Completas de Sigmund Freud. Edição Standard Brasileira. Rio de Janeiro: Imago, 1996.

O Mal-Estar na Civilização (1930-1936). In: Obras Psicológicas Completas de Sigmund

Freud. Edição Standard Brasileira. Rio de Janeiro: Imago, 1996. 


\section{RevistAleph}

HUXLEY, Aldous. Admirável mundo novo (1946). São Paulo: Globo, 2009.

LACAN, Jacques. Introdução teórica às funções da psicanálise em criminologia (1950). In: Os

Escritos. Rio de Janeiro: Jorge Zahar, 1998.

O desejo e a sua interpretação (1957-1958). Rio de Janeiro: J. Zahar, inédito. (O seminário, 6).

O lugar da psicanálise na medicina (1966). Revista Opção Lacaniana, $n^{\circ} 32$, São Paulo, Dezembro de 2001.

MEIRIEU, Philippe; MILLER, Jacques-Allain. Jacques-Alain Miller pergunta a Philippe Meirieu sobre a hegemonia do cognitivismo. Revista Cien Digital, n. 3, Março de 2008.

MILLER, Jacques-Alain. Curso de Orientação Lacaniana, 2007-2008.

Projeto de Lei no 867, de 2015. Disponível em:

https://www.camara.leg.br/proposicoesWeb/fichadetramitacao?idProposicao=1050668.

RAHME, Mônica; MRECH, Leny Magalhães. Proliferação de objetos e empuxo ao gozo: impactos do discurso capitalista na educação. In: 0 declínio dos saberes e o mercado do gozo. São Paulo, 2010.

TIZIO, Hebe. La posición de los profesionales en los aparatos de gestión del síntoma. In: TIZIO, Hebe (orgs). Reinventar el vínculo educativo: aportaciones de la Pedagogía Social y del Psicoanálisis. Barcelona: Gedisa, 2003.

VOLTOLINI, Rinaldo. A “inclusão” conduz ao pior. In: COLóQUIO DO LEPSI IP/FE - USP, 5. Anais. São Paulo, 2004.

O discurso do capitalista, a psicanálise e a educação. In: ARAÚJO, Nina V. de; AIRES, Suely; VERAS, Viviane (orgs). Linguagem e gozo. Campinas: Mercado de Letras, 2007.

. Educação e psicanálise. Rio de Janeiro: Zahar, 2011.

Data do envio: 29/04/2019.

Data do aceite: $25 / 11 / 2020$. 